\title{
Cancer incidence, mortality and survival trends in Canada, 1970-2007
}

\section{Kachuri, MPH (1); P. De, PhD (1, 2); L. F. Ellison, MSc (3); R. Semenciw, MSc (4); The Advisory Committee on Canadian Cancer Statistics}

This article has been peer reviewed.

\begin{abstract}
Introduction: Monitoring cancer trends can help evaluate progress in cancer control while reinforcing prevention activities. This analysis examines long-term trends for selected cancers in Canada using data from national databases.

Methods: Annual changes in trends for age-standardized incidence and mortality rates between 1970 and 2007 were examined by sex for 1) all cancers combined, 2) the four most common cancers (prostate, breast, lung, colorectal) and 3) cancers that demonstrate the most recent notable changes in trend. Five-year relative survival for 1992-2007 was also calculated.

Results: Incidence rates for all primary cancer cases combined increased $0.9 \%$ per year in males and $0.8 \%$ per year in females over the study period, with varying degrees of increase for melanoma, thyroid, liver, prostate, kidney, colorectal, lung, breast, and bladder cancers and decrease for larynx, oral, stomach and cervical cancers. Mortality rates were characterized by significant declines for all cancers combined and for most cancers examined except for melanoma and female lung cancer. The largest improvements in cancer survival were for prostate, liver, colorectal and kidney cancers. While the overall trends in mortality rates and survival point to notable successes in cancer control, the increasing trend in incidence rates for some cancers emphasize the need for continued efforts in prevention.
\end{abstract}

Keywords: cancer surveillance, incidence, mortality, survival, risk factors

\section{Introduction}

At the beginning of 2007, nearly 750000 Canadians had a diagnosis of cancer in the previous 10 years. ${ }^{1}$ Cancer is the leading cause of death in Canada, ${ }^{2}$ with $82 \%$ of all cancer deaths occurring in those aged 60 years and over. ${ }^{1}$ By 2036, about 10.9 million Canadians will be aged 65 years or older, ${ }^{3}$ which will lead to more new cancer cases and create significant demands for cancer care.

An examination of historical cancer trends can help us predict future patterns of this disease and evaluate progress in cancer control, thus allowing public health professionals to reinforce existing cancer prevention and control activities.

This analysis examines long-term trends for (1) all cancers combined, (2) the four most common cancers in Canada (prostate, female breast, lung, colorectal), and (3) those cancers shown to have the most notable changes in their incidence or mortality trends in the past decade (stomach, liver, thyroid, larynx, melanoma, bladder, kidney, cervix). To our knowledge, this is the most up-to-date and comprehensive examination of long-term Canadian cancer trends. As such, it can be used to compare with reported trends in other countries. More importantly, trends are discussed in the context of major cancer risk factors and associated health behaviours to provide perspective on the possible determinants of disease.

\section{Methods}

\section{Data sources}

We took cancer incidence data from 1992 to 2007 from the July 2010 version of the Canadian Cancer Registry, a personoriented, population-based database. ${ }^{4}$ Data for the earlier period, from 1970 to 1991, are from the National Cancer Incidence and Reporting System, a tumour-oriented database established in $1969 .^{5}$ Mortality data were from the Canadian Vital Statistics Death Database. Population estimates were from Statistics Canada's Demographic Estimates Compendium $2010 .^{6}$

We created a file containing records of invasive cancer cases for all ages and in situ bladder cancer cases (except from the province of Ontario) using the International Agency for Research on Cancer multiple primary coding rules. ${ }^{7}$ Cancer cases were classified based on the International Classification of Diseases for Oncology, 3rd Edition. ${ }^{8}$ Cancer group definitions are provided elsewhere. ${ }^{1}$ For cancer deaths, the underlying causes of death were selected according to the International Classification of Diseases and classified to version 10 (ICD-10). ${ }^{9}$

Author references:

1. Dalla Lana School of Public Health, University of Toronto, Toronto, Ontario, Canada

2. Cancer Control Policy, Canadian Cancer Society, Toronto, Ontario, Canada

3. Health Statistics Division, Statistics Canada, Ottawa, Ontario, Canada

4. Chronic Diseases Prevention and Control, Public Health Agency of Canada, Ottawa, Ontario, Canada

Correspondence: Prithwish De, Canadian Cancer Society, 55 St Clair Ave West, Suite 300, Toronto, ON M4V 2Y7; Tel.: 416-934-5335; Fax: 416-961-4189; Email: prithwish.de@cancer.ca 


\section{Statistical analysis}

We calculated age-specific rates for each year and then standardized them to the 1991 Canadian population to obtain the age-standardized incidence rates (ASIR) and mortality rates (ASMR). Trends over the short and long terms were analyzed by calculating the annual percent change (APC) and average annual percent change (AAPC) in rates, respectively, using Joinpoint version 3.5.1 software. ${ }^{10}$ Joinpoint uses piecewise regression to model the change in ASIR and ASMR on the log scale. While other approaches, such as a polynomial fit to the data, could be used, Joinpoint characterizes trends more succinctly by transforming the slope of each segment into an average percent change. ${ }^{11}$ A minimum of 5 years of data before and after a point of change was required to identify a new trend. Models were tested using the Monte Carlo permutation method ( $p=.05$ level of significance). Any statistically significant changes in trend are described here as "decreasing" or "declining" or, conversely, "increasing."

Relative survival analyses were based on a publicly available algorithm ${ }^{12}$ which we adapted slightly. The focus of this analysis was on all primary cancer cases aged 15 to 99 years at diagnosis. Mortality follow-up through December 31, 2007, was determined by record linkage of the Canadian Cancer Registry to the Canadian Vital Statistics Death Database and from information reported by provincial/territorial cancer registries. Data from Quebec were excluded because the method of ascertaining the date of diagnosis of cancer cases in this province differed from that of the other provinces ${ }^{13,14}$ and because of issues in correctly ascertaining the vital status of cases diagnosed in Quebec within the Canadian Cancer Registry. We derived 5 -year relative survival ratio (RSR) estimates using the cohort method for 1992 to 1994, 1996 to 1998, and 2000 to 2002 and the period method for 2005 to 2007 . Because more recent data were unavailable, expected survival data for 2005 to 2007 (used in the derivation of relative survival) were assumed to be the same as in 2000 to 2002. Further information on the survival methodology used is provided elsewhere. ${ }^{15}$

\section{Results}

In 2007, 85430 new cancer cases and 36569 cancer deaths were reported in males, and 78099 new cases and 33026 deaths occurred in females. Together, the most frequently diagnosed cancers (prostate, female breast, colorectal and lung) accounted for $55 \%$ and $52 \%$ of all new cancer diagnoses in males and females, respectively, as well as $50 \%$ and $51 \%$ of cancer deaths in each sex.

\section{Trends in incidence and mortality}

\section{All cancers combined}

Table 1 shows the APCs and AAPCs for cancer incidence. The ASIRs for all cancers combined for 1970 and 2007 were higher in males (1970: 330.4 per 100000 ; 2007: 463.2 per 100000$)$ than in females (1970: 272.0 per 100000; 2007: 362.3 per $100000)$. The rate increased at an average of $0.9 \%$ per year in males and $0.8 \%$ per year in females over the study period.

The APCs and AAPCs for cancer mortality are shown in Table 2. As for incidence, the ASMR for all cancers combined was higher in males (1970: 228.4 per 100000 ; 2007: 200.1 per 100000) than in females (1970: 152.1 per 100000 ; 2007: 141.2 per 100000 ) but decreased at a rate of $0.3 \%$ per year in males and $0.2 \%$ per year in females over the study period.

\section{Selected cancers}

Between 1970 and 2007, there was an overall upward trend in male incidence rates (Figure 1) for melanoma (AAPC: $3.7 \%)$ and for thyroid (3.6\%), liver $(3.5 \%)$, prostate $(2.2 \%)$, kidney $(1.8 \%)$, colorectal $(0.6 \%)$ and bladder cancers $(0.4 \%)$ but a declining trend for larynx $(0.8 \%)$, oral $(1.4 \%)$ and stomach $(2.1 \%)$ cancers. Incidence rates increased in females for thyroid (AAPC: $4.4 \%$ ), lung (4.4\%), melanoma (2.9\%), kidney $(2.1 \%)$, liver $(1.9 \%)$, breast $(0.5 \%)$ and bladder cancers $(0.5 \%)$ while decreasing AAPCs were observed for cervix $(2.5 \%)$ and stomach cancers (2.3\%).

For most cancers, mortality rates between 1970 and 2007 were characterized by statistically significant decreases (Figure 2) with the exception of female lung cancer
(AAPC: $4.0 \%$ ) and melanoma (AAPC: $2.3 \%$ for males, $0.8 \%$ for females), for which increases were observed.

The trends for certain cancers are worth highlighting. For example, the prostate cancer incidence rate peaked twice, in 1993 and 2001 (Table 1 and Figure 1). Following the first peak, the incidence rate decreased (APC: 5.2\%) until 1997, after which the rate climbed at $3.9 \%$ per year to a second peak in 2001, followed by a period of non-significant decline. We observed only one period of increase in the mortality rate for this cancer, between 1977 and 1993, which preceded a continuous decline that has further accelerated since 2001 (Table 2).

The incidence rate of lung cancer increased by $3.7 \%$ per year in males between 1970 and 1983. This was followed by a period of non-significant change until 1990 when the incidence rate started declining (Table 1). In females, the incidence rate has been increasing since 1970 but has slowed from $8.4 \%$ per year (1970-1983) to $3.8 \%$ per year (19831992 ) and finally to $1.4 \%$ per year (1992-2007). Lung cancer mortality in males followed a trajectory similar to incidence: the rate increased $(2.7 \%$ per year) until 1983 , remained stable $(0.0 \%$ per year) from 1983 to 1992, and then began declining at an annual rate of $2.2 \%$ (Table 2). In contrast, the lung cancer mortality rate in females has continued to increase since 1970 , from $6.9 \%$ per year (1970-1985) to 3.6\% per year (1985-1994) and finally $1.0 \%$ per year (1994-2007).

Larynx cancer incidence rates increased from 1970 until 1980 in males (APC: $3.6 \%$ ) and until 1989 in females $(3.2 \%$ per year). Male incidence rates declined at $1.0 \%$ per year from 1980 to 1992 , after which the decrease accelerated to $3.4 \%$ per year. Female incidence rate declined at an annual rate of $3.1 \%$ since 1989 . The mortality rate increased from 1970 until 1988 for males ( $0.8 \%$ per year) and until 1991 for females (1.9\% per year), followed by significant declines in both sexes.

Bladder cancer incidence rates increased from 1970 to 1981 (males: 3.3\% per year; females: $3.5 \%$ per year), but the trend 


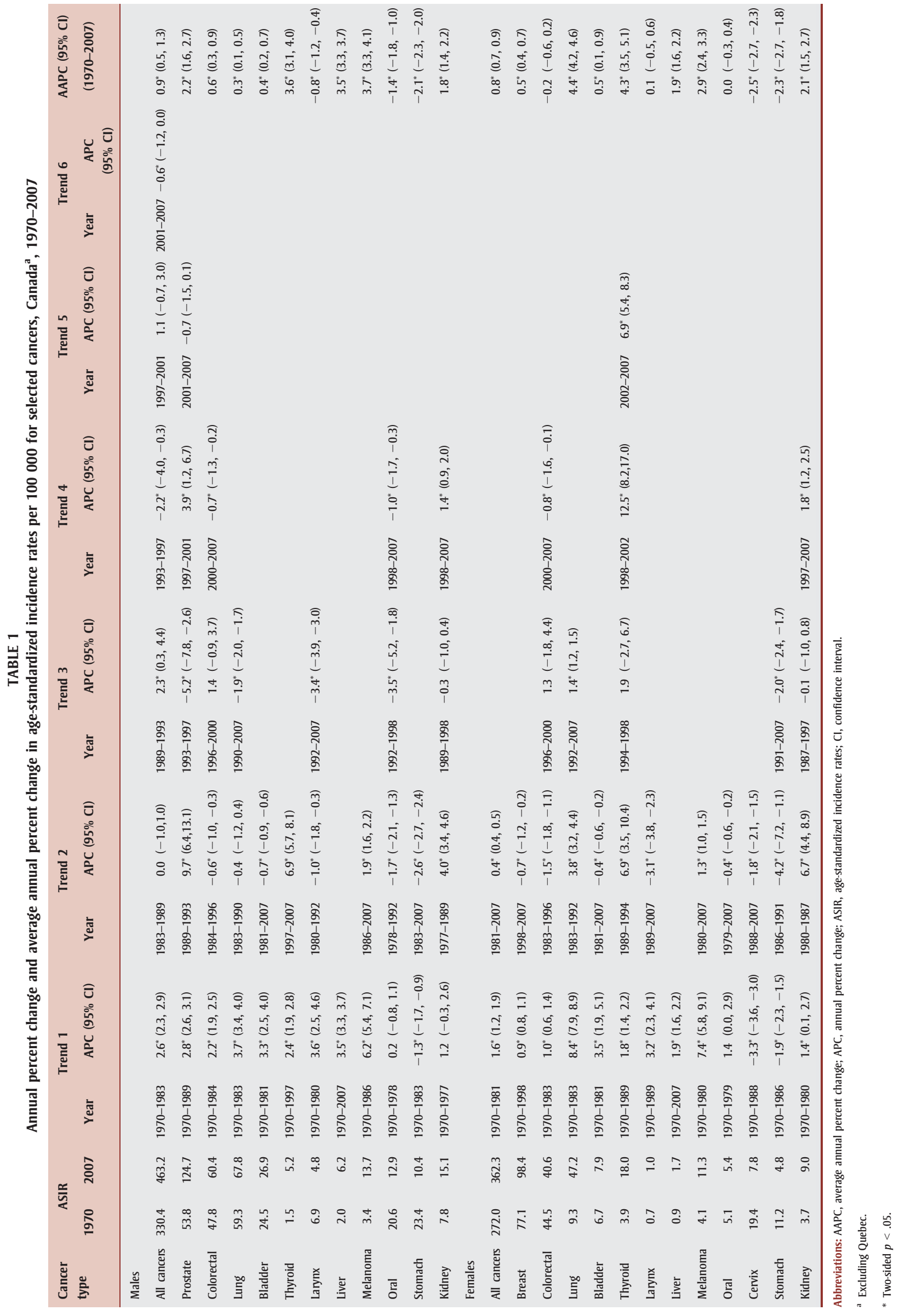




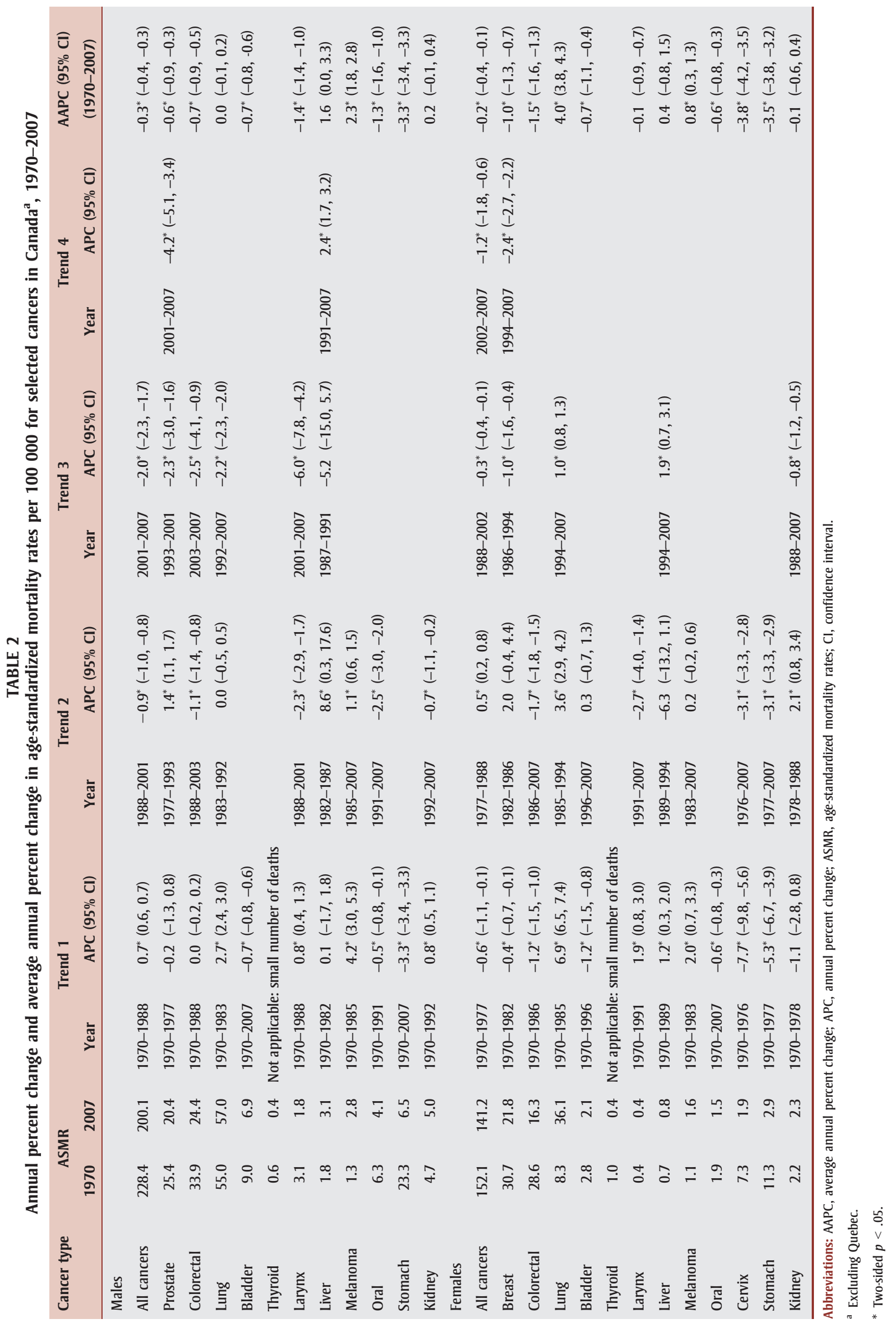


FIGURE 1

Average annual percent change in age-standardized incidence rates for selected cancers in males and females, Canada, 1970-2007

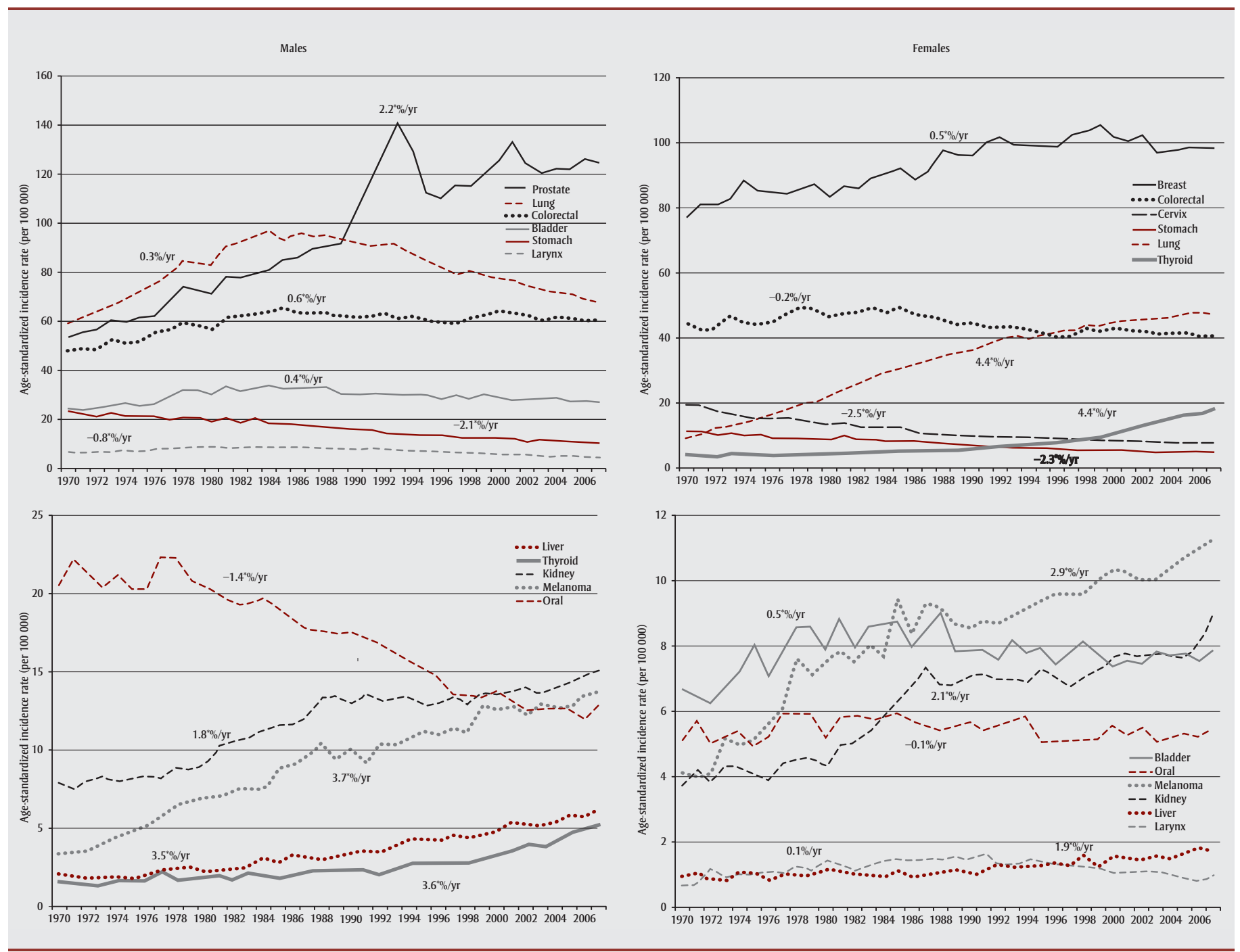

Note: Joinpoint analyses with up to 5 joinpoints were based on age-adjusted rates (per 100000 persons).

${ }^{a}$ Excluding Quebec.

* Two-sided $p<.05$.

reversed in 1981 when incidence rates began decreasing (males: $0.7 \%$ per year; females: $0.4 \%$ per year). Mortality rates, on the other hand, have decreased over the entire study period for males $(0.7 \%$ per year) and from 1970 to 1996 for females (1.2\% per year).

The overall incidence rate of kidney cancer in males increased over two periods, 1977 to 1989 and 1998 to 2007. We observed two similar periods of increase in females, from 1980 to 1987 and from 1997 to 2007. In contrast, the male mortality rate increased from 1970 to 1992 but has been decreasing since then, while the female mortality rate increased from 1978 to 1988 and has since declined.

The incidence rate of thyroid cancer has been steadily increasing since 1970 in both sexes. In males, the rate increased at $2.4 \%$ per year between 1970 and 1997 and then accelerated to $6.9 \%$ per year until 2007. More notably, in females the incidence rate has varied from $1.8 \%$ per year between 1970 and 1989, 6.9\% per year between 1989 and 1994, 12.5\% per year between 1998 and 2002, and more recently (2002-2007), 6.9\% per year. Thyroid cancer mortality rates were too low to permit a Joinpoint analysis.

\section{Trends in survival}

Between 1992 to 1994 and 2005 to 2007, the 5-year age-standardized RSR for all cancers combined rose by 6.8 percentage points to $62 \%$ (Table 3 ). Larger gains in survival were seen for males than females (8.5 vs. 5.0 percentage points) over this period, resulting in considerable narrowing in the previous gap.

The degree of improvement in the 5-year RSR varied considerably for individual cancers. The largest improvements of approximately 8 to 10 percentage points were for prostate, liver, colorectal and kidney cancers. Small improvements of 2 
FIGURE 2

Average annual percent change in age-standardized mortality rates for selected cancers in males and females, Canada ${ }^{\mathrm{a}}, 1970-2007$

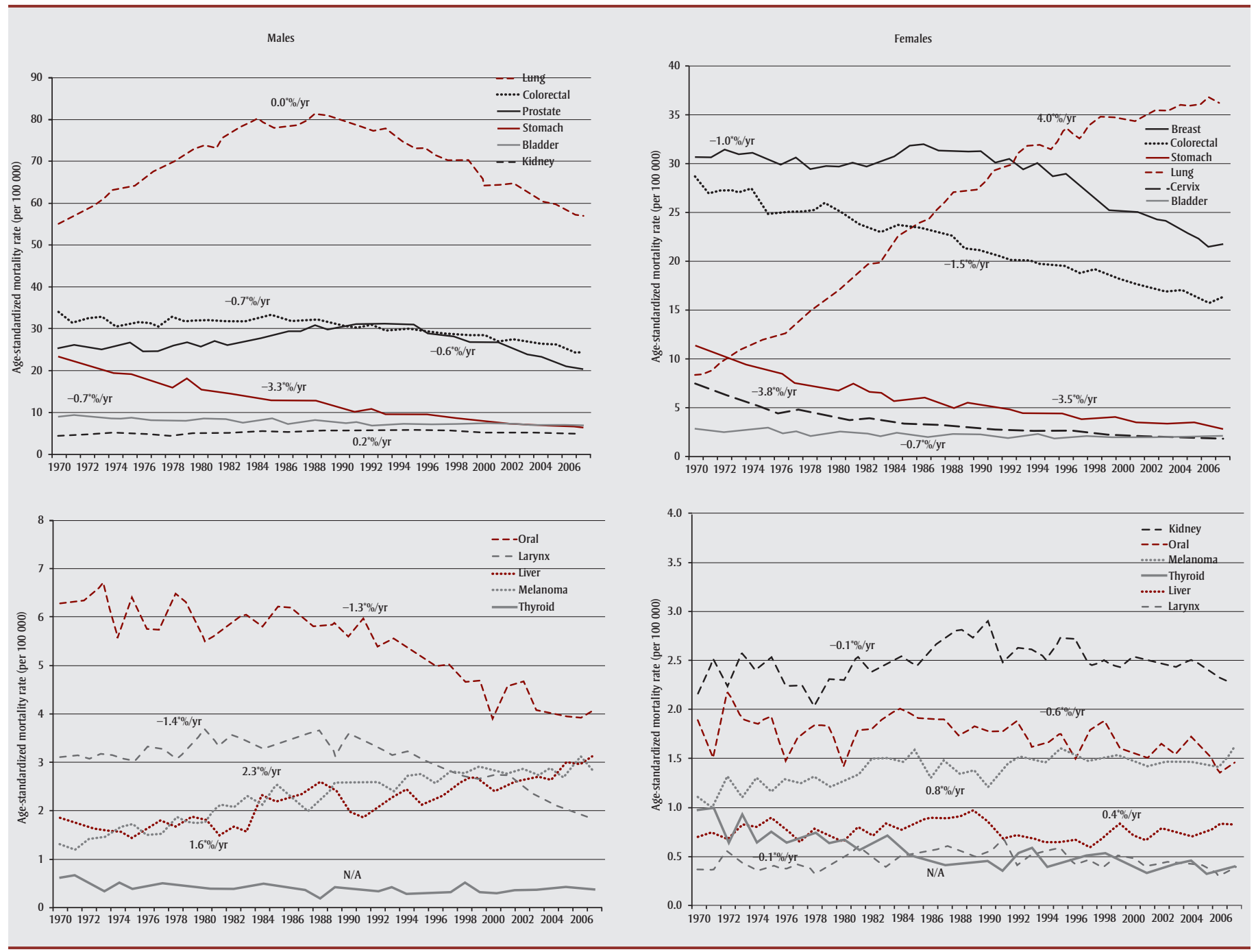

Abbreviation: N/A, not applicable.

Note: Joinpoint analyses with up to 5 joinpoints were based on age-adjusted rates (per 100000 persons).

${ }^{\text {a }}$ Excluding Quebec.

* Two-sided $p<.05$.

to 3 percentage points were observed for lung, larynx, cervical and oral cancers. There was no apparent improvement for bladder cancer over the study period. Disparities between the sexes in survival gains favoured females (data not shown) and included oral (3.7\% females vs. $1.1 \%$ males), larynx (4.1\% vs. $1.5 \%)$, lung $(3.5 \%$ vs. $1.3 \%)$ and stomach cancers (6.3\% vs. $4.5 \%)$.

\section{Discussion}

Over the nearly 40-year period between 1970 and 2007, incidence rates for all cancers combined increased significantly in both Canadian males and females. While rates have stabilized in males since 1993, in females the overall incidence rate appears to have started plateauing only recently. These overall trends were driven largely by the three most common cancers in males (i.e. lung, prostate and colorectal) and in females (i.e. breast, lung and colorectal).

Cancer mortality rates in both sexes peaked in 1988 and have since declined largely due to reductions in mortality rates in the four leading causes of cancer death (i.e. lung, colorectal, prostate and breast cancers). The gains in 5-year RSR since the period 1992 to 1994 for all cancers combined and for selected cancers suggest improvements in treatment and early detection of certain cancers as well as advances in supportive and general medical care.

\section{Trends in leading cancers}

\section{Prostate cancer}

Little is known about the risk factors for prostate cancer aside from age. Although androgens are critical for prostate cancer growth, it is unclear whether high androgen levels can promote cancer initiation. ${ }^{16}$ A link with physical activity has been 
TABLE 3

Five-year age-standardized relative survival ratios for selected cancers ${ }^{\mathrm{a}}$ by time period, Canadab, 1992-2007

\begin{tabular}{|c|c|c|c|c|c|}
\hline \multirow[t]{2}{*}{ Cancer type } & \multicolumn{4}{|c|}{ RSR $^{\mathbf{c}}, \%(95 \% \mathrm{Cl})$} & \multirow{2}{*}{$\begin{array}{c}\text { Change }^{d} \\
\text { 1992-1994 } \\
\text { to } 2005-2007\end{array}$} \\
\hline & 1992-1994 & 1996-1998 & 2000-2002 & 2005-2007 & \\
\hline All cancers & $56(55-56)$ & 57 (57-57) & $60(60-61)$ & $62(62-63)$ & 6.8 \\
\hline Male & $54(54-54)$ & $55(55-56)$ & $60(60-60)$ & $62(62-63)$ & 8.5 \\
\hline Female & 57 (56-57) & 58 (58-59) & $60(60-60)$ & $62(62-63)$ & 5.0 \\
\hline Prostate & 87 (86-87) & 90 (89-90) & 94 (94-95) & 96 (96-97) & 9.8 \\
\hline Female breast & $82(82-83)$ & 85 (85-86) & $87(86-87)$ & 88 (87-88) & 5.6 \\
\hline Colorectal & $56(55-56)$ & 58 (57-59) & $61(60-61)$ & $64(64-65)$ & 8.6 \\
\hline Lung & 14 (13-14) & $15(14-15)$ & 15 (15-15) & 16 (16-17) & 2.6 \\
\hline Bladder & 73 (72-74) & $71(70-72)$ & $71(70-72)$ & $72(71-73)$ & -0.3 \\
\hline Thyroid & 93 (92-94) & 94 (93-95) & 96 (96-97) & 98 (97-98) & 4.9 \\
\hline Larynx & $62(60-64)$ & $63(61-65)$ & 62 (59-64) & $64(61-66)$ & 1.9 \\
\hline Liver & $10(8-11)$ & $12(11-14)$ & 17 (15-18) & $18(17-20)$ & 8.7 \\
\hline Melanoma & $84(83-86)$ & 87 (86-87) & 89 (88-90) & 89 (89-90) & 4.9 \\
\hline Oral & 60 (59-61) & 59 (58-61) & 61 (59-62) & $62(61-64)$ & 2.3 \\
\hline Cervix & 70 (68-71) & 70 (69-72) & 73 (71-75) & 72 (70-73) & 2.2 \\
\hline Stomach & 19 (18-21) & $22(20-23)$ & $22(21-23)$ & 25 (23-26) & 5.1 \\
\hline Kidney & 60 (58-61) & $62(60-63)$ & $64(63-65)$ & $67(66-69)$ & 7.7 \\
\hline
\end{tabular}

Abbreviations: $\mathrm{Cl}$, confidence interval; RSR, relative survival ratio.

${ }^{\text {a }}$ For persons aged 15 to 99 years at diagnosis.

b Excluding Quebec.

c Results derived using both the cohort (1992-1994, 1996-1998 and 2000-2002) and period (2005-2007) methods.

d Absolute difference in percentage points.

suggested $^{17}$ but the evidence remains inconclusive. ${ }^{18,19}$ Obesity is only weakly associated with the development of prostate cancer, but there is some suggestion that it could increase the risk of death and metastasis. ${ }^{20-22}$

Despite uncertainty about the benefits and risks of prostate cancer testing using the prostate-specific antigen (PSA) test, its use is widespread. $^{23}$ According to national health surveys, the proportion of males aged 35 plus who had ever had a PSA test was $53.8 \%$ in $2008 .^{24}$ Two recent randomized trials have not confirmed PSA as a viable population-based screening tool for reducing prostate cancer deaths, ${ }^{25,26}$ and it is not currently recommended in Canada as a population-based screening test. Nonetheless, the prostate cancer incidence rate in Canada rose sharply following the introduction of the PSA test in 1988. The incidence rate peaked in 1993 and then again in 2001. This second date could be explained by the publicity that year surrounding the then federal health minister's disclosure that he had been diagnosed with prostate cancer.

The prostate cancer mortality rate in Canada has declined since 1995, returning to pre-1970 levels in 2007. Early detection of prostate cancer through widespread screening is believed to have contributed to the decreasing mortality trend in the United States, ${ }^{27}$ and there is some suggestion that a similar phenomenon is responsible for the mortality and survival trends in Canada. ${ }^{28}$ The nearly 10 percentage point gain in the 5-year RSR since 1992 to 1994 may also, to some degree, be explained by the greater availability of effective hormonal therapy for early and advanced-stage disease in the mid-1980s ${ }^{29}$ followed by the introduction of watchful waiting and advances in combined radiation and hormonal therapy for prostate cancer which occurred in the 1990s. ${ }^{30}$

\section{Breast cancer}

The female breast cancer incidence rate in Canada rose steadily at $0.9 \%$ per year between 1970 and 1998, after which the rate started to decline at $0.7 \%$ per year. Trends in breast cancer incidence likely reflect long-term changes in hormonal factors (e.g. early age at menarche, late age at menopause, breastfeeding, oral contraceptive use, hormone replacement therapy use) and the increasing uptake of mammography screening, especially throughout the 1980s. ${ }^{31}$ The first provincial organized breast cancer screening program was implemented in Canada in 1988, and all 10 Canadian provinces had established programs by $1998 .^{32}$ While all provincial programs offer mammography screening to women aged 50 to 69 years, some are also open to those in their $40 \mathrm{~s}$ and those older than 69 years. ${ }^{32}$

National health surveys show that the proportion of postmenopausal females aged between 50 and 69 years who selfreport having a mammogram within the previous two years has increased from $40.5 \%$ in 1990 to $72.5 \%$ in $2008 .{ }^{32}$ The brief decline in the breast cancer incidence rate between 1998 and 2005 could be due to the exhaustion of undiagnosed prevalent cases as a result of screening and/or to a reduction in breast cancer risk as a result of postmenopausal women avoiding hormone replacement therapy following reports from the Women's Health Initiative and earlier investigations that highlighted the associated risks. ${ }^{33}$

Although postmenopausal obesity and alcohol consumption can increase breast cancer risk ${ }^{34,35}$ and physical activity can reduce risk, ${ }^{36}$ the impact of these factors in the Canadian context is not clear.

The breast cancer mortality rate started declining in 1986 at $1.0 \%$ per year and accelerated to $2.4 \%$ per year after 1994 . The lower mortality and improved survival likely resulted from the increasing use of opportunistic mammography testing prior to the establishment of provincial screening programs, the increasing use of hormonal and adjuvant chemotherapy ${ }^{37,38}$ and the shift in clinical practice to breastconserving surgery and lumpectomy. ${ }^{39,40}$

\section{Lung cancer}

Smoking is a causal factor in the development of lung, oral cavity and larynx 
cancers, among others. ${ }^{41}$ The effects of smoking tobacco on lung cancer incidence are observed only after a latency period of approximately 25 years. ${ }^{42}$ The prevalence of smoking in Canada has decreased substantially between 1965 and 2007 from $61 \%$ to $20 \%$ in males and from $38 \%$ to $18 \%$ in females aged 15 plus years. ${ }^{43}$ After reaching a peak in 1965, tobacco use dropped in response to the widely publicized negative health effects of cigarette smoking reported by the U.S. Surgeon General. ${ }^{44}$ This resulted in a decline in the male lung cancer incidence rate after this peaked in 1983 and in male mortality rate after this peaked in 1988. By 2007, the male lung cancer incidence rate had fallen to nearly the same level as in 1970 .

The lung cancer mortality rate in females, on the other hand, has continued to increase, albeit at a slower pace since the mid-2000s. Smoking rates in females started to decrease about 15 years after those in males, remaining between $37 \%$ and 39\% until 1979. ${ }^{43}$ Though there is still an upward trend in lung cancer incidence and mortality rates in Canadian females, encouraging U.S. data show that the female lung cancer death rate in that country is decreasing following a plateau. ${ }^{45}$

\section{Colorectal cancer}

Colorectal cancer is associated with several modifiable risks including obesity, physical inactivity, consumption of red and processed meat and smoking. ${ }^{46}$ The prevalence of obesity (i.e. body mass index $\geq 30 \mathrm{~kg} / \mathrm{m}^{2}$ ) in Canadian adults has increased from $13.8 \%$ to $23.9 \%$ over the 30 years until 2007/2009. ${ }^{47,48}$ Prevalence was higher in females (15.9\%) than in males (11.5\%) in 1978/1979, but this pattern has now reversed such that slightly more males $(24.2 \%)$ than females $(23.6 \%)$ were considered obese in $2007 / 2009$. $^{47,48}$

The colorectal cancer incidence rate in males has returned to a level seen in the early 1980s, while in females the rate is now lower than that in the 1970s. The decline in the male death rate began in 1988 , while in females the rate continued a decline that began before 1970. These differing trends suggest different risk factors. It has been suggested that increasing use of hormone replacement therapy in women prior to the early 2000s may have contributed to the declining risk of colon cancer in this sex. ${ }^{34,49}$

The decline in colorectal cancer death rates in both sexes began before the growing uptake of screening through the organized programs largely implemented across Canadian provinces in the past six years. Testing of occult blood in the stools of average-risk individuals aged 50 plus years $^{50}$ and colonoscopy for high-risk individuals have been the predominant approaches for the early detection and removal of pre-cancerous polyps, ${ }^{51}$ aimed at lowering colorectal cancer incidence and mortality. Currently, the average participation rate for those aged between 50 and 74 years in provincial organized screening programs is $32.2 \% .^{52}$ Greater uptake of screening will likely further reduce colorectal cancer incidence and mortality rates in Canada.

\section{Emerging trends in other cancers}

\section{Thyroid cancer}

Thyroid cancer has been one of the most rapidly increasing cancers in Canada in recent years. ${ }^{1,53}$ The steep upward trend could be due to the increasing use of diagnostic technologies such as fineneedle aspiration for the detection of subclinical tumours, increased exposure to diagnostic ionizing radiation that could promote the initiation of new tumours, or increased exposure to an as yet unidentified environmental risk factor. ${ }^{54,55}$ Ionizing radiation remains the most established risk factor for thyroid cancer, but mounting evidence points to a possible role of body weight and female reproductive factors, both of which probably operate in carcinogenesis through hormonal pathways. Despite the growing incidence rate, thyroid cancer mortality rates have remained low and the 5-year RSR in both sexes (98\%) is the highest of all the major cancers.

\section{Liver cancer}

The most common type of primary liver cancer, hepatocellular carcinoma, is associated with low survival and high mortality. Between 1970 and 2007, incidence of liver cancer in Canada has increased faster in males (3.5\% per year) than in females (1.9\% per year). Gender differences in incidence may be due to the different distribution of liver cancer risk factors, such as heavy drinking (i.e. above the low-risk drinking guidelines ${ }^{56}$ ), smoking and hepatitis infection. Population-based estimates show that the heavy drinking rate in Canada has increased between 1989 and 2007 from $18.9 \%$ to $25 \%$ for males and $7.2 \%$ to $9.6 \%$ for females. ${ }^{57,58}$

In developed countries the greatest burden of liver cancer is due to chronic hepatitis C infection rather than hepatitis $B$ virus (HBV) infection, which is more prevalent in other parts of the world. ${ }^{59}$ A link has also been hypothesized between obesity and liver cancer, which is believed to occur through non-alcoholic fatty liver disease. ${ }^{60}$ Such an association places greater importance on the increasing obesity rate in Canada, which has climbed from $14 \%$ in the late 1970 s to $24 \%$ in $2007 / 2009 .{ }^{47,48}$

\section{Melanoma}

Ultraviolet radiation can cause all forms of skin cancer. $^{61}$ Although the increasing incidence of melanoma in Canada could be in part due to better detection, ${ }^{62,63}$ it more likely reflects greater recreational UV exposure from sun and artificial tanning. The prevalence of tanning is about $49 \%$ in Canadian women and $28 \%$ in Canadian men aged 16 to 24 years according to the 2006 National Sun Survey. ${ }^{64}$

Of all the major cancers, melanoma has had the second greatest increase in mortality rate (after liver cancer in males and lung cancer in females) since 1970. Although the mortality rate in females has remained essentially unchanged since 1983 , in males the mortality rate rose by $1.1 \%$ per year over a similar time period (1985-2007). The lower 5-year RSR ${ }^{65}$ and the higher proportion of more advancedstage cases in males ${ }^{66}$ reflects the higher melanoma mortality rate in men compared with women. However, the upward rise in male mortality has been diminishing, possibly due to improved survival through earlier detection and better treatments for melanoma including surgical resection. $^{67}$ 


\section{Kidney}

The reason behind the increasing kidney cancer incidence rate, while not clear, could reflect several changes including the availability of newer diagnostic techniques $^{68,69}$ as well as the increased prevalence of obesity and hypertension, both of which are important risk factors. ${ }^{70}$ In fact, $55 \%$ of kidney cancers in Canadian males and $27 \%$ in females may be attributable to being overweight or obese. ${ }^{71}$

\section{Trends in cancers with decreasing rates}

\section{Stomach, cervix, oral, larynx, bladder}

Smoking is an important risk factor shared by stomach, oral, larynx, bladder and cervical cancers. The decreasing incidence and mortality trends for these cancers can be largely explained by trends in smoking, which dropped dramatically after 1965 for males and after 1979 for females in Canada. ${ }^{43}$ Changes in other risk factors have also influenced observed trends. For example, the decline in stomach cancer rates since the 1970 s resulted from improvements in diet including higher intakes of fruits and vegetables and lower intake of salt-preserved foods, ${ }^{72}$ and more recently, an increased recognition and treatment of Helicobacter pylori bacterium infection, a key stomach cancer risk factor. ${ }^{73}$

Cervical cancer incidence and mortality rates in Canada continued to decline during the study period due to the widespread use of the Papanicolaou (Pap) test screening introduced in $1949 .{ }^{74}$ As a complement to Pap screening, immunization of females aged 9 to 26 years with a human papillomavirus (HPV) vaccine (approved in Canada in $2008^{75}$ ) is expected to further reduce the long-term incidence and mortality rates. With the growing recognition of HPV in the etiology of certain oral cancers, such as those arising in the tonsils and oropharynx, ${ }^{76,77}$ HPV immunization could also help shape future oral cancer trends in Canada.

\section{Limitations}

Our analysis had several limitations. First, we attempted to explain observed cancer trends with regard to populationbased data on risk factors that are largely cross-sectional and mostly self-reported. Second, because of data availability, we were able to consider only a subset of modifiable lifestyle factors that influence disease rates. Moreover, we considered only modifiable risk factors that may be etiologically relevant to adult-onset cancers but not those unique to pediatric and adolescent cancers. Third, the data sources, methods for cancer registration, as well as completeness and accuracy of data used for deriving incidence estimates can vary across Canada. ${ }^{1}$ Such differences can lead to minor under- and overestimates of disease rates, which are discussed more fully elsewhere. ${ }^{1}$ Finally, relative survival estimates for the years 2005 to 2007 may be overestimated due to the necessity of using expected survival data from an earlier time period in their derivation. The effect would likely be greatest for cancers with older case distributions such as prostate cancer.

\section{Conclusion}

The downward trends in incidence rates for certain cancers and mortality rates for most cancers in Canada support the success of various strategies including cancer screening, prevention through lifestyle and behavioural changes, and improvements in environmental hygiene. Despite these successes, the need for reinforcing primary prevention remains important as several cancers continue to show stable or rising incidence trends.

\section{Acknowledgements}

This work was produced with in-kind contributions from the Canadian Cancer Society, the Public Health Agency of Canada and Statistics Canada. The authors thank the Steering Committee of Canadian Cancer Statistics for their critical review of the manuscript: Heather Chappell (Canadian Cancer Society); Dagny Dryer (PEI Cancer Treatment Centre); Maureen MacIntyre (Cancer Care Nova Scotia); Loraine Marrett (Cancer Care Ontario); Les Mery (Public Health Agency of Canada); and Hannah Weir (U.S. Centers for Disease Control and Prevention).

The Canadian Cancer Registry is maintained by Statistics Canada. It is made up of data supplied by the provincial and territorial cancer registries whose cooperation is gratefully acknowledged.

\section{Conflict of interest: none.}

\section{References}

1. Canadian Cancer Society's Steering Committee on Cancer Statistics. Canadian Cancer Statistics 2011. Toronto (ON): Canadian Cancer Society; 2011.

2. Statistics Canada. Leading causes of death in Canada, 2009 [Internet]. Ottawa (ON): Minister of Industry; 2012 [cited 2012 Sept 19] [Statistics Canada, Catalogue No.: 84-215-X). Available from: http://www statcan.gc.ca/bsolc/olc-cel/olc-cel?catno $=84-215-x \& l a n g=$ eng

3. Statistics Canada. Population projections for Canada, provinces and territories, 2009 to 2036 [Internet]. Ottawa (ON): Minister of Industry; 2010 [cited 2011 Aug 5]. [Statistics Canada, Catalogue No.: 91-250-X]. Available from: http://www.statcan.gc.ca /daily-quotidien/100526/dq100526b-eng.htm

4. Statistics Canada. Cancer incidence in Canada 2007 and 2008 [Internet]. Ottawa (ON): Minister of Industry; 2010 [cited 2011 Aug 5]. [Statistics Canada, Catalogue No.: 82-231$\mathrm{X}$. Available from: http://www.statcan.gc .ca/pub/82-231-x/82-231-x2009001-eng.htm

5. Band P, Gaudette LA, Hill GB, Holowaty EJ, Huchcroft SA, Johnston GM, et al. The making of the Canadian Cancer Registry: cancer incidence in Canada and its regions, 1969-1988. Ottawa (ON): Canadian Council of Cancer Registries, Health and Welfare Canada, Statistics Canada, 1993.

6. Statistics Canada. Demographic estimates compendium, 2010. CANSIM Table 0510001, released on September 29, 2010. Ottawa (ON): Minister of Industry; 2010.

7. Parkin DM, Chen VW, Ferlay J, Galceran J, Storm HH, Whelan SL. Comparability and quality control in cancer registration. Lyon (FR): World Health Organization; 1994.

8. Fritz A, Percy C, Jack A, Shanmugarathan $\mathrm{K}$, Sobin L, Parkin DM, et al., editors. International classification of diseases for oncology, 3rd ed. Geneva (CH): World Health Organization; 2000. 
9. International statistical classification of diseases and related health problems, 10th rev. Geneva $(\mathrm{CH})$ : World Health Organization; 1992.

10. Joinpoint regression program, v.3.5.1 [computer program]. Rockville (MD): Statistical Research and Applications Branch, National Cancer Institute; 2011.

11. Kim HJ, Fay MP, Feuer EJ, Midthune DN. Permutation tests for joinpoint regression with applications to cancer rates. Stat Med. 2000;19:335-51.

12. Dickman PW. Estimating and modelling relative survival using SAS [Internet]. [Stockholm (SE)]: [publisher unknown]; [cited 2010 Jan 4]. Available from: http://www.pauldickman.com/rsmodel /sas_colon

13. Ellison LF, Gibbons L; Canadian Cancer Survival Analysis Group. Five-year relative survival from prostate, breast, colorectal and lung cancer. Health Rep. 2001;13(1): 23-34.

14. Louchini R. La survie au cancer pour les nouveaux cas déclarés au Québec en 1992. Quebec (QC): Institut national de santé publique du Québec; 2002.

15. Cancer Survival Statistics [Internet]. Ottawa (ON): Statistics Canada; 2011 [cited 2011 Jul 5]. [Statistics Canada, Catalogue No.: 82226-X]. Available from: http://www.statcan .gc.ca/pub/82-226-x/82-226-x2011001-eng .htm

16. Wang D, Tindall DJ. Androgen action during prostate carcinogenesis. Methods Mol Biol. 2011;776:25-44.

17. Vainio H, Bianchini $F$, editors. Weight control and physical activity. Lyon (FR): International Agency for Research on Cancer; 2002. (Vainio H, editor. IARC handbook of cancer prevention; vol 6).

18. Pan SY, DesMeules M. Energy intake, physical activity, energy balance, and cancer: epidemiologic evidence. Methods Mol Biol. 2009;472:191-215.

19. Friedenreich CM, Neilson HK, Lynch BM. State of the epidemiological evidence on physical activity and cancer prevention. Eur J Cancer. 2010;46(14):2593-604.
20. MacInnis RJ, English DR. Body size and composition and prostate cancer risk: systematic review and meta-regression analysis. Cancer Causes Control. 2006;17(8): 989-1003.

21. Giovannucci E, Liu Y, Platz EA, Stampfer MJ, Willett WC. Risk factors for prostate cancer incidence and progression in the health professionals follow-up study. Int $\mathrm{J}$ Cancer. 2007;121(7):1571-8.

22. Gong Z, Agalliu I, Lin DW, Stanford JL, Kristal AR. Obesity is associated with increased risks of prostate cancer metastasis and death after initial cancer diagnosis in middle-aged men. Cancer. 2007;109(6): 1192-202.

23. Levy I. Prostate cancer: the epidemiologic perspective. Can J Oncol. 1994;4 Suppl 1:4-7.

24. Statistics Canada. Canadian Community Health Survey, Cycle 4.1, 2007 [computer file]. Ottawa (ON): Health Statistics Division; 2007.

25. Andriole GL, Crawford ED, Grubb RL 3rd, Buys SS, Chia D, Church TR, et al. Mortality results from a randomized prostate-cancer screening trial. N Engl J Med. 2009;360(13): 1310-9.

26. Schroder FH, Hugosson J, Roobol MJ, Tammela TL, Ciatto S, Nelen V, et al. Screening and prostate-cancer mortality in a randomized European study. N Engl J Med. 2009;360(13):1320-8.

27. Hankey BF, Feuer EJ, Clegg LX, Hayes RB, Legler JM, Prorok PC, et al. Cancer surveillance series: interpreting trends in prostate cancer--part I: evidence of the effects of screening in recent prostate cancer incidence, mortality, and survival rates. J Natl Cancer Inst. 1999;91(12):1017-24.

28. Nam RK, Klotz LH. Trends in prostate cancer screening: Canada. In: Ankerst DP, Tangen CM, Thompson IM, editors. Current clinical urology: prostate cancer screening, 2nd ed. New York (US): Humana Press; 2009. pp. 23-33.

29. Meng MV, Grossfeld GD, Sadetsky N, Mehta SS, Lubeck DP, Carroll PR. Contemporary patterns of androgen deprivation therapy use for newly diagnosed prostate cancer. Urology. 2002;60 (3 Suppl 1):7-11.
30. Kupelian PA, Buchsbaum JC, Elshaikh MA, Reddy CA, Klein EA. Improvement in relapse-free survival throughout the PSA era in patients with localized prostate cancer treated with definitive radiotherapy: year of treatment an independent predictor of outcome. Int J Radiat Oncol Biol Phys. 2003;57(3):629-34.

31. Holford TR, Cronin KA, Mariotto AB, Feuer EJ. Changing patterns in breast cancer incidence trends. J Natl Cancer Inst Monogr. 2006;(36):19-25.

32. Shields M, Wilkins K. An update on mammography use in Canada. Health Rep. 2009;20(3):7-19.

33. De P, Neutel CI, Olivotto I, Morrison H. Breast cancer incidence and hormone replacement therapy in Canada. J Natl Cancer Inst. 2010;102(19):1489-95.

34. Reeves GK, Pirie K, Beral V, Green J, Spencer E, Bull D. Cancer incidence and mortality in relation to body mass index in the Million Women Study: cohort study. BMJ. 2007;335(7630):1134.

35. Alcohol consumption and ethyl carbamate. Lyon (FR): International Agency for Research on Cancer; 2010. (IARC monographs on the evaluation of carcinogenic risks to humans; vol 96).

36. Friedenreich $\mathrm{C}$. The role of physical activity in breast cancer etiology. Semin Oncol. 2010;37(3):297-302.

37. Harlan LC, Abrams J, Warren JL, Clegg L, Stevens J, Ballard-Barbash R. Adjuvant therapy for breast cancer: practice patterns of community physicians. J Clin Oncol. 2002;20(7):1809-17.

38. Mariotto A, Feuer EJ, Harlan LC, Wun LM, Johnson KA, Abrams J. Trends in use of adjuvant multi-agent chemotherapy and tamoxifen for breast cancer in the United States: 1975-1999. J Natl Cancer Inst. 2002;94(21):1626-34.

39. Edwards BK, Brown ML, Wingo PA, Howe HL, Ward E, Ries LA, et al. Annual report to the nation on the status of cancer, 19752002, featuring population-based trends in cancer treatment. J Natl Cancer Inst. 2005;97(19):1407-27. 
40. NIH consensus conference. Treatment of early-stage breast cancer. JAMA. 1991; 265(3):391-5.

41. Tobacco smoke and involuntary smoking. Summary of data reported and evaluation. Lyon (FR): International Agency for Research on Cancer; 2004. (IARC monographs on the evaluation of carcinogenic risks to humans; vol 83.)

42. Kleinsmith LJ, editor. Principles of cancer biology, $1^{\text {st }}$ edition. San Francisco (CA): Benjamin Cummings; 2005.

43. Reid J, Hammond D. Tobacco use in Canada: patterns and trends, 2011 edition. Waterloo (ON): Propel Centre for Population Health Impact, University of Waterloo; 2011.

44. The Surgeon General's Advisory Committee on Smoking and Health. Smoking and health: report of the Advisory Committee to the Surgeon General of the Public Health Service. Washington (DC): US Department of Health, Education and Welfare, 1964. (Public Health Service Publication, No. 1103.)

45. Kohler BA, Ward E, McCarthy BJ, Schymura MJ, Ries LA, Eheman C, et al. Annual report to the nation on the status of cancer, 1975-2007, featuring tumors of the brain and other nervous system. J Natl Cancer Inst. 2011;103(9):714-36.

46. Food, nutrition, physical activity, and the prevention of cancer: a global perspective [Internet]. Washington (DC): World Cancer Research Fund/American Institute for Cancer Research; 2007 [cited 2012 Sept 19]. Available from: http://www.dietandcancerreport .org/cancer_resource_center/downloads /Second_Expert_Report_full.pdf

47. Tjepkema M. Adult obesity. Health Rep. 2006;17(3):9-25.

48. Statistics Canada. Canadian Health Measures Survey: Cycle 1 data tables. Ottawa (ON): Minister of Industry; 2010.

49. Newcomb PA, Zheng Y, Chia VM, Morimoto LM, Doria-Rose VP, Templeton A, et al. Estrogen plus progestin use, microsatellite instability, and the risk of colorectal cancer in women. Cancer Res. 2007;67 (15):7534-9.
50. Mandel JS, Church TR, Bond JH, Ederer F, Geisser MS, Mongin SJ, et al. The effect of fecal occult-blood screening on the incidence of colorectal cancer. N Engl J Med. 2000;343(22):1603-7.

51. Schatzkin A, Freedman LS, Dawsey SM, Lanza E. Interpreting precursor studies: what polyp trials tell us about large-bowel cancer. J Natl Cancer Inst. 1994;86(14): 1053-7.

52. Pan-Canadian System Performance Working Group. 2010 system performance report. Toronto (ON): Canadian Partnership Against Cancer; 2010.

53. Liu S, Semenciw R, Ugnat AM, Mao Y. Increasing thyroid cancer incidence in Canada, 1970-1996: time trends and ageperiod-cohort effects. Br J Cancer. 2001; 85(9):1335-9.

54. Kent WD, Hall SF, Isotalo PA, Houlden RL, George RL, Groome PA. Increased incidence of differentiated thyroid carcinoma and detection of subclinical disease. CMAJ. 2007;177(11):1357-61.

55. How J, Tabah R. Explaining the increasing incidence of differentiated thyroid cancer. CMAJ. 2007;177(11):1383-4.

56. Butt P, Beirness D, Cesa F, Gliksman L, Paradis C, Stockwell T. Alcohol and health in Canada: a summary of evidence and guidelines for low-risk drinking. Ottawa $(\mathrm{ON})$ : Canadian Centre on Substance Abuse; 2011.

57. CANSIM Table 105-0501. Health indicator profile, annual estimates, by age group and sex, Canada, provinces, territories, health regions (2011 boundaries) and peer groups, occasional [data file]. Ottawa (ON): Statistics Canada; [cited 2012 Sept 19]. Available from: http://www5.statcan.gc.ca/cansim $/ \mathrm{a} 05$ ?lang $=$ eng\&id $=1050501$

58. Ahmad N, Flight J, Singh VA, Poole N, Dell CA. Focus on gender - a national survey of Canadians' use of alcohol and other drugs Canadian Addiction Survey (CAS). Ottawa (ON): Health Canada; 2008.

59. Parkin DM. The global health burden of infection-associated cancers in the year 2002. Intl J Cancer. 2006;118(12):3030-44.
60. Chuang SC, La Vecchia C, Boffetta P. Liver cancer: descriptive epidemiology and risk factors other than HBV and HCV infection. Cancer Lett. 2009;286(1):9-14.

61. Solar and ultraviolet radiation. Lyon (FR): International Agency for Research on Cancer; 1992. (IARC monographs on the evaluation of carcinogenic risks to humans; vol 55.)

62. Jemal A, Devesa SS, Hartge P, Tucker MA. Recent trends in cutaneous melanoma incidence among whites in the United States. J Natl Cancer Inst. 2001;93(9):678-83.

63. Welch HG, Woloshin S, Schwartz LM. Skin biopsy rates and incidence of melanoma: population based ecological study. BMJ. 2005;331(7515):481.

64. The Ontario Sun Safety Working Group. Insight on cancer: sun exposure and protective behaviours in Ontario. An Ontario report based on the 2006 Second National Sun Survey. Toronto (ON): Canadian Cancer Society; 2010 [cited 2011 Jun 13]. Joint publication of Cancer Care Ontario. Available from: http://uvnetwork.ca /InsightonCancerSunExposureandProtective BehavioursinOntarioFinal.pdf

65. Joosse A, de Vries E, Eckel R, Nijsten T, Eggermont AM, Holzel D, et al. Gender differences in melanoma survival: female patients have a decreased risk of metastasis. J Invest Dermatol. 2011;131(3):719-26.

66. Howlader $\mathrm{N}$, Noone AM, Krapcho $M$, Neyman N, Aminou R, Waldron W, et al., editors. SEER Cancer Statistics Review, 1975-2008. Bethesda (MD): National Cancer Institute; 2011 [cited 2011 Dec 13]. Available from: http://seer.cancer.gov/csr /1975_2008/

67. Morton DL. Current management of malignant melanoma. Ann Surg. 1990;212(2): 123-4.

68. Jayson M, Sanders H. Increased incidence of serendipitously discovered renal cell carcinoma. Urology. 1998;51(2):203-5.

69. Leslie JA, Prihoda T, Thompson IM. Serendipitous renal cell carcinoma in the post-CT era: continued evidence in improved outcomes. Urol Oncol. 2003;21(1):39-44. 
70. Chow WH, Gridley G, Fraumeni JF Jr, Jarvholm B. Obesity, hypertension, and the risk of kidney cancer in men. N Engl J Med. 2000;343(18):1305-11.

71. Pan SY, Johnson KC, Ugnat AM, Wen SW, Mao Y. Association of obesity and cancer risk in Canada. Am J Epidemiol. 2004; 159(3):259-68.

72. Howson CP, Hiyama T, Wynder EL. The decline in gastric cancer: epidemiology of an unplanned triumph. Epidemiol Rev. 1986;8(1):1-27.

73. Schistosomes, liver flukes and Helicobacter pylori. Lyon (FR): International Agency for Research on Cancer; 1994. (IARC monographs on the evaluation of carcinogenic risks to humans; vol 61.)

74. Liu S, Semenciw R, Probert A, Mao Y. Cervical cancer in Canada: changing patterns in incidence and mortality. Int $\mathrm{J}$ Gynecol Cancer. 2001;11(1):24-31.

75. National Advisory Committee on Immunization. Statement on human papillomavirus vaccine. Can Commun Dis Rep. 2007;33(2):1-32.

76. A review of human carcinogens: biological agents. Lyon (FR): International Agency for Research on Cancer; 2012. (IARC monographs on the evaluation of carcinogenic risks to humans; vol 100b.)

77. Auluck A, Hislop G, Bajdik C, Poh C, Zhang L, Rosin M. Trends in oropharyngeal and oral cavity cancer incidence of human papillomavirus (HPV)-related and HPVunrelated sites in a multicultural population: the British Columbia experience. Cancer. 2010;116(11):2635-44. 